LAWRENCE LIVERMORE NATIONAL LABORATORY
Image-Based Vehicle Identification Technology for Homeland Security Applications

G. A. Clark, Ph.D.

October 8, 2002 
This document was prepared as an account of work sponsored by an agency of the United States Government. Neither the United States Government nor the University of California nor any of their employees, makes any warranty, express or implied, or assumes any legal liability or responsibility for the accuracy, completeness, or usefulness of any information, apparatus, product, or process disclosed, or represents that its use would not infringe privately owned rights. Reference herein to any specific commercial product, process, or service by trade name, trademark, manufacturer, or otherwise, does not necessarily constitute or imply its endorsement, recommendation, or favoring by the United States Government or the University of California. The views and opinions of authors expressed herein do not necessarily state or reflect those of the United States Government or the University of California, and shall not be used for advertising or product endorsement purposes.

This work was performed under the auspices of the U.S. Department of Energy by University of California, Lawrence Livermore National Laboratory under Contract W-7405-Eng-48. 


\section{White Paper:}

\section{Image-Based Vehicle Identification Technology for Homeland Security Applications}

Grace A. Clark, Ph.D.

October 8, 2002

Lawrence Livermore National Laboratory

7000 East Ave., L-130

Livermore, CA 94550-6349

(965) 423-9759 (Office)

(965) 422-2495 (FAX)

clark9@llnl.gov 


\section{ABSTRACT / EXECUTIVE SUMMARY}

The threat of terrorist attacks against US civilian populations is a very real, near-term problem that must be addressed, especially in response to possible use of Weapons of Mass Destruction. Several programs are now being funded by the US Government to put into place means by which the effects of a terrorist attack could be averted or limited through the use of sensors and monitoring technology. Specialized systems that detect certain threat materials, while effective within certain performance limits, cannot generally be used efficiently to track a mobile threat such as a vehicle over a large urban area. The key elements of an effective system are an image feature-based vehicle identification technique and a networked sensor system. We have briefly examined current uses of image and feature recognition techniques to the urban tracking problem and set forth the outlines of a proposal for application of LLNL technologies to this critical problem.

The primary contributions of the proposed work lie in filling important needs not addressed by the current program:

1. The ability to create vehicle "fingerprints," or feature information from images to allow automatic identification of vehicles. Currently, the analysis task is done entirely by humans. The goal is to aid the analyst by reducing the amount of data he/she must analyze and reduce errors caused by inattention or lack of training. This capability has broad application to problems associated with extraction of useful features from large data sets.

2. Improvements in the effectiveness of LLNL's WATS (Wide Area Tracking System) by providing it accurate threat vehicle location and velocity. Model predictability is likely to be enhanced by use of more information related to different data sets.

We believe that the LLNL can accomplish the proposed tasks and enhance the effectiveness of the system now under development. 


\section{Contents}

\subsection{Problem Description}

2.0 Assessment of the State of the Art

2.1 Outside LLNL

2.2 At LLNL

3.0 Technical Approach

4.0 Proposed Plan for LLNL Work

5.0 Summary and Conclusions

References

Appendices: 


\title{
Image-Based Vehicle Identification Technology for Homeland Security Applications
}

\author{
Grace A. Clark, Ph.D.
}

October 8,2002

\subsection{Introduction}

The threat of terrorist attacks against US civilian populations is a very real, near-term problem that must be addressed, especially in response to possible use of Weapons of Mass Destruction. Several programs are now being funded by the US Government to put into place means by which the effects of a terrorist attack could be averted or limited through the use of sensors and monitoring technology. Specialized systems that detect certain threat materials, while effective within certain performance limits, cannot generally be used efficiently to track a mobile threat such as a vehicle over a large urban area. The key elements of an effective system are an image feature-based vehicle identification technique and a networked sensor system. We have briefly examined current uses of image and feature recognition techniques to the urban tracking problem and set forth the outlines of a proposal for application of LLNL technologies to this critical problem.

This report represents about two weeks of work and provides a brief investigation into the problem. If the program decides to pursue the ideas further, a more thorough followon investigation would be appropriate at that time.

\subsection{The Problem}

The threat is terrorism. The generic problem is to identify and track vehicles entering and moving about a facility, using images from cameras and data from a variety of sensors. Examples of facilities include nuclear processing plants, power plants, weapons laboratories, government buildings/compounds, coliseums, laboratories, military bases, ports, border crossings, etc. In general applications, the sensors can possibly be widely varied in type, including optical cameras, induction loops, infrared cameras, magnetic sensors, transponders, etc. Because of current program plans at LLNL, the focus of this report is on cameras (usually in the visible wavelengths) that produce images that can be used along with data from other sensors, when appropriate. 
Current program plans call for collecting images to be analyzed by human analysts, who track detected vehicles and make decisions regarding the meaning of the images and actions to take. In addition, the program has algorithms for tracking vehicles once they are detected (Wide Area Tracking System (WATS), by Christopher Cunningham - see the References). The key system element that is missing is the ability to create feature information (or "fingerprints") of vehicles and classify/identify the vehicles automatically.

Our focus in this report is on creating vehicle "fingerprints" or feature information along with classification/identification algorithms for two main purposes: (1) It is advantageous to automate the mind-numbing low-level image analysis tasks that are done well by computers and allow the analyst to focus on the upper-level analysis and decision-making tasks that are best done by a human. This approach can greatly mitigate analyst fatigue (along with its accompanying errors) and the amount of data the analyst must process. (2) The vehicle feature information and classification results can be used directly by the vehicle tracking algorithms (WATS). Currently, WATS is under-utilized, in the sense that it receives information about the existence of a vehicle, but it receives no information about the characteristics of the vehicle. WATS, along with some other supplemental algorithms, could be used to greater effect if it had that information.

Current program plans call for:

- A demonstration in the Spring of 2003 (LLNL). Humans will do the vehicle recognition.

- Multi-Agency demonstration in the 2004 for the DOE and FBI.

Three sensor packages have been proposed by LLNL and SNLL for use in a vehicle identification system. The attributes of these packages are summarized below. The current plans for a Phase 1 test (to be held in Spring, 2003) call for 18 nodes ( 8 VIS nodes plus 10 Enhanced Nodes). Figure 1.1 shows a proposed physical configuration for using the sensors at a facility.

Enhanced Node (LLNL/RSL), \$75K

- Camera

- Communication system

- Gamma detector

- Neutron detector

- $\quad$ Energy spectrum measurement (gamma and neutron) - measures counts vs. energy

\section{License Plate Reader Node (LLNL/Pulnix), \$20K}

- Progressive scan camera

- Light sensor

- Strobe unit

- Laser range finder

- Computer/system controller 
- Ethernet link

VIS (Vehicle Imaging System) Node (LLNL), \$5K

- Camera

- Video server

- Communication system

Clearly, a major strength of the VIS Node is its low price in dollars. As depicted in Figure 1.1, we propose a system network in which radiation detectors are NOT necessary at every node. In such a system, radiation detections are key to detecting a suspect vehicle, but not necessary at every node for tracking it. Much of the information gathering for the tracking task can be passed off to the camera/image nodes, resulting in great financial savings. If the VIS node is effective for vehicle identification and tracking, it could provide hardware cost savings of millions of dollars in a complex environment such as a city. The major uncertainty (at this time) regarding the VIS Node is the level of effectiveness it can achieve, when used in conjunction with appropriate target recognition and tracking algorithms. We propose that a study of the effectiveness be undertaken.

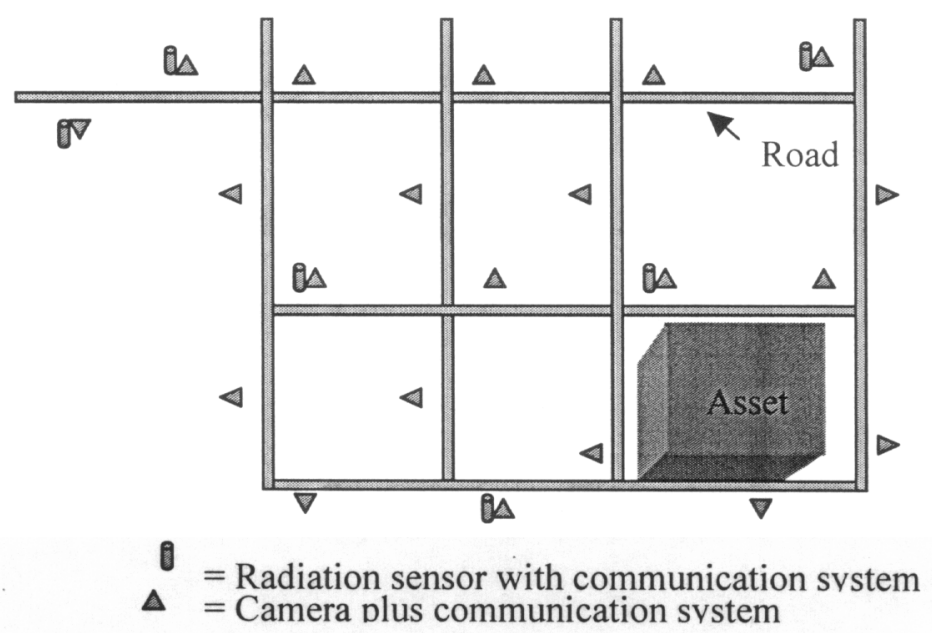

Figure 1.1 A possible configuration for a facility to be protected is exemplified in this illustration. The number of radiation sensors required is reduced because cheaper cameras are used. 


\section{Preliminary Assessment of the State of the Art}

\section{Industry / Outside LLNL}

The author has conducted a literature search, focusing mostly on scientific books, journals and conference papers. Selected titles and abstracts are given in the Appendix. In addition, some outside organizations have been contacted, as follows.

Pulnix America, Inc., 1330 Orleans Drive, Sunnyvale, CA 94089, (800) 445-5444.

Jim Alves of Pulnix presented the company's capabilities at LLNL on October 4, 2002. The following briefly summarizes their systems.

- Sensors: Single-frame cameras along with range finders and light sensors to measure illumination conditions.

- Two types of vehicle recognition systems; (1) License Plate Reading (LPR) system and (2) Vehicle "Fingerprint" matching system.

- Sponsors/applications: Tollbooth enforcement monitoring in highway systems (detecting non-paying customers, etc.), monitoring customers of casinos, etc.

- Applicability: Some of this technology might be applicable to our problem - in particular, the hardware systems. We expect that their feature extraction and vehicle classification/identification algorithms could serve as supplement for an LLNL system, but would not stand alone. The system depends upon having a known database of information for each vehicle it inspects (license number, vehicle description, etc.). Our application cannot make such assumptions.

Other contacts with whom the author has spoken:

- Thomas Jourdan, FBI technology transfer agent at LLNL. Tom has provided me with contacts (listed next) at FBI labs.

- FBI Engineering Research Facility (ERF) (Phil Mirarchi) and Physical Surveillance Unit (Jay Chamberlain) - I spoke with Jay. I have been unable to date to reach Phil Mirarchi.

Other outside contacts not yet made, except through literature search in some cases:

- Other Private Companies

- "PATH" Program at UCB - Transportation Systems Research

- Cognitech.com - Virgil Kohlhepp of LLNL said they did vehicle recognition work with DARPA, but it may not be useful enough for our application.

- Government organizations - DARPA, DOD - Literature searches only

- Secret Service

- Port authorities 


\section{LLNL}

Technical Groups at LLNL

* EE/EETD Advanced Communications and Signal Processing Group (Group Leader: Steven G. Azevedo)

* EE/DSED Signal/Image Processing and Control Group (Group Leader: Jose E. Hernandez)

* EE/EETD Decision Sciences Group (Group Leader: Bill Hanley)

* Computations Dept. (Task Leader: Chandrika Kamath)

* Computations, EE, NAI program(s): Database systems expertise,

* CAPS," the "Counter-proliferation Analysis and Planning System"

* ISCR (Institute for Scientific Computing Research).

Individuals with particularly relevant expertise at LLNL

* Chris Cunningham - Wide Area Tracking System ("WATS"), for tracking vehicles in traffic. The system does routing. The DEA uses it for tracking drug traffic. Route optimization.

* Virgil Kohlhepp - Smart camera system for security applications. The camera system has a built-in FPGA (Field Programmable Gate Array), which allows the implementation of image processing algorithms directly on the camera. This gives the ability to do important processing operations on-line on the camera, without the need for off-line processing.

* Grace A. Clark - ATR, signal/image processing, image sequence analysis, etc. (see references and C.V.)

* Leonid Zsap - Image sequence analysis.

* Dave Paglieroni, HIRIS program and LDRD/SI, "ICE."

* Thomas Jourdan, FBI Technical Liaison at LLNL (B132S, X23556)

* Bill Lennon and Fred Savage - working on container security (imaging) for ports.

\section{LLNL Systems}

* LLNL radiation sensors

* Current and proposed programs in Homeland Security

* Superblock - security systems - Chuck Fetterman

* LLNL Security Dept.

\section{The Literature}

The vehicle (or object) identification/classification/tracking literature is varied. The general object recognition literature is rich with results, many of which can be used for vehicle recognition. A key point, however, is that real-world vehicle recognition systems are optimized for a particular application. This is what one would expect in any good engineering system. In particular, the problem is constrained to maximize the use of prior information, because that results in higher performance, and extremely high performance is specified by the sponsor (often they want $\mathrm{P}$ (Correct Classification $)=99.5 \%$ or higher!). Thus, many variables found in 
theoretical papers are forced to be fixed or approximately fixed. These include camera angle, illumination, lack of occlusion, specific unique information about the vehicle (license number), required transponders on the vehicle, required magnetic or inductance loop sensors on (or in) the roadway, required lane discipline, etc. Some of these practical systems offer us partial help, but many constrained solutions are simply not realistic for our application. We are not likely to be able to require a transponder in every vehicle, use embedded roadway sensors in every facility or require that every license plate be registered with the Department of Motor Vehicles in a particular state. License plates may be stolen or nonexistent, etc. Terrorists do not feel constrained by rules.

Consider License Plate Reading (LPR) as an example application. The OCR (Optical Character Recognition) literature is extensive. However, for license plate reading, we have found that industrial companies who actually read license plates (especially Pulnix) often do not use OCR. License plate reading is not as easy as reading text on a page. Experienced people find that difficulties in obtaining images consistent in illumination, contrast, lack of occlusion, camera angle, the state (California, etc) in which the vehicle is registered), and other variables make the common OCR techniques ineffective for highway applications. They use pattern-matching algorithms instead.

Image-based vehicle (or object) recognition/tracking systems can use single images or image sequences. Image sequences can provide motion features that can be very valuable for classifying the object (or vehicle). At this time, we cannot be sure of the value that would be added by motion features for our application. That would require a bit of study. The Pulnix system used for simple toll enforcement applications performs well using single images.

A great deal of work has been done by DARPA, DOD, et. al. in recognition of military vehicles. Some vehicle recognition work has been done at LLNL (see the References). The results are generally promising, with limitations inherent in particular applications.

The author believes that sufficient algorithmic tools for automatic target recognition (ATR) are available, and expertise at LLNL is well established in this area. The key to any ATR system is good data because ATR systems have the famous "garbage-in-garbage-out" property. If we can obtain good quality, reasonably consistent imagery, taken with reasonable constraints, the ATR part of the counter-terrorism (CT) problem should be soluble, given reasonable resources.

\subsection{Technical Approach}

The following technical issues must be considered:

* Typically more than one "hit" is needed for threat detection

* Image resolution - is it sufficient? Range, speed, FOV, focus

* False alarms caused by radiation sources in hospitals, veterinarian clinics, etc. can stress the system and cause it to be ignored ("crying wolf"). 
Technical goals include the following:

o Detect, alert, track - Detect a suspect vehicle, alert appropriate people, systems, and track the vehicle.

o Minimize the number of radiation detectors required, because they are very expensive.

o Reduce the load/dependence on human operators - automate as much as possible. Provide human operators with an efficient screening and analysis tool.

o Develop vehicle "fingerprint," or feature information for use by detection/classification algorithms.

- Once a vehicle is detected/classified using a radiation detector, hand off the tracking task to a system of video sensors and analysis algorithms.

- Perform a set of feasibility demonstration controlled tests at LLNL and have results to present at Design Reviews and demonstrations in Spring, 2003 and Spring 2004 (demonstration in a city)

- Integrate information of various types: Sensor data (radiation, video, etc.), intelligence, database information (e.g. vehicle logs, rental vehicles, etc.)

Preliminary list of vehicle features to consider:

Vehicle model, make, year (e.g. Dodge RAM utility van, 2000)

License plate number

Search database for information related to the license number:

Is it a rented vehicle?

Owner, name on the registration

Stolen vehicle reports

Watch lists from various agencies

Persons in the vehicle - male, female, large, small, multiple males in the vehicle?

Radiation spectrum? Features of the radiation spectrum?

Vehicle size, weight

Vehicle color

Thermal signature?

Radar topography?

Motion features from an image sequence?

\subsection{Proposed Plan for LLNL Work}

- Start the project by doing all of the license plate and vehicle tracking visually by human operators. Add the implementations of the automated system(s) later-perhaps in the second year or later.

- Examine utility of available (LLNL and commercial) technology wherever possible. 
The following is a very brief preliminary project description for accomplishing the proposed work, assuming a funding level of 2 FTE/year.

\section{Tasks}

1. Detailed problem definition for our application

2. ATR Algorithm R\&D

3. Tracking Algorithm R\&D

4. Performance Metric R\&D

3. Controlled Tests with Real Data

4. System Implementation and Testing

5. System deployment for final testing/demo

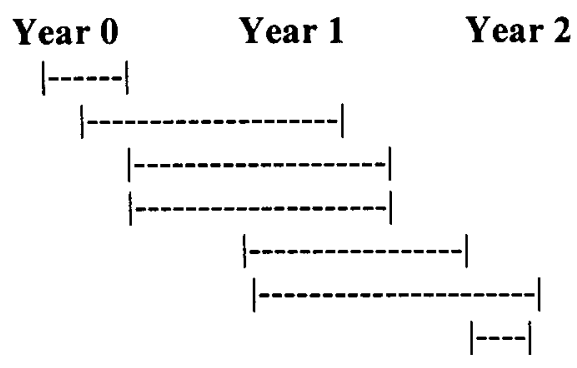

\subsection{Summary and Conclusions}

The primary contributions of the proposed work lie in filling important needs not addressed by the current program:

1. The ability to create vehicle "fingerprints," or feature information from images to allow automatic identification of vehicles. Currently, the analysis task is done entirely by humans. The goal is to aid the analyst by reducing the amount of data he/she must analyze and reduce errors caused by boredom.

2. The need to improve the effectiveness of the WATS (Wide Area Tracking System) by providing it powerful vehicle "fingerprint" information and identifications, rather than the less informational "detection of the existence of a vehicle," which is currently used.

We believe that the LLNL can accomplish the proposed tasks and enhance the effectiveness of the system now under development.

\section{ACKNOWLEDGMENTS}

The author gratefully acknowledges the important contributions to this work made by her colleagues. Scott McAllister (program leader) is in charge of the overall project. Steve Peglow has provided technical direction and several others, such as Thomas Jourdan (FBI), Chris Cunningham (Q Division) and Jim Alves (Pulnix Corp), have shared valuable insights and experience. 


\section{REFERENCES}

1. R. Bryant, J. Baker, C. T. Cunningham, F. Dowla, R. Leach and S. Peglow, "Scalable Wireless Sensor Networks with Distributed Data Interpretation, LLNL Report, LDRD Final Report for Project Number 99-ERD-014, 1999.

2. G. Sleefe, S. Peglow, R. Hamrick, "Applications of Unattended Ground Sensors to Stationary Targets," Proceedings of the SPIE, Volume 3081-04, Orlando Fl., April 1997.

3. C. T. Cunningham, "Detection and Tracking of a Stochastic Target using Multiple Measurements", LLNL, UCRL-ID-122786, 11/95.

4. J. Alves, "Image Processing Technology for Violation Enforcement," Pulnix Corp., Presentation, October 21, 2002. 


\section{CURRICULUM VITAE OF G.A. CLARK}

\section{Education}

Ph.D. University of California, Santa Barbara, Electrical and Computer Engineering, 1981

MSEE Purdue University, Electrical Engineering Honors Program, 1974

BSEE Purdue University, Electrical Engineering Honors Program, 1972

Areas of Expertise Theory and application of automatic target recognition, computer vision, sensor fusion, pattern recognition/neural networks, estimation/detection, signal/image processing and control.

University of California Lawrence Livermore National Laboratory (LLNL), 1974-Present

1996-Present Project Leader, LLNL, and Research Associate, U.C. Davis. Event picking for seismic oil exploration (with Shell Oil), nonlinear state estimation for missile system navigation and guidance, image processing for the National Ignition Facility (NIF) optical alignment system, clinical heart valve classification, damage detection for large mechanical structures (bridges, buildings, etc.) and sensor fusion for detecting underground objects. Ph.D. committee member, UCD.

1995 Research Associate, on Professional Research and Teaching Leave (sabbatical) from LLNL at U.C. Davis. Research in image fusion for remote sensing, and event picking for seismic oil exploration (for Shell Oil).

1991-1994 Project Engineer for Imaging and Vision, Engineering Research Division, Project Leader for Automatic Target Recognition and Image Processing. Nuclear Test Division, LLNL, and Program Leader for Automatic Target Recognition for the Airborne Standoff Mine Detection Program. Program development and technical project leadership. Developed an automatic target recognition system for detecting buried land mines using neural networks, and fusing data from infrared, visible and ground penetrating radar sensors. Lead projects in clinical heart valve classification, and developed image sequence analysis algorithms. Lead 20 engineers with a budget of more than $\$ 2 \mathrm{M} / \mathrm{year}$.

1989-1991 Principal Investigator, Eng. Research Div. and Nuclear Energy Systems Division. Conducted research in seismic array processing for verifying nuclear test ban treaties, image processing for reconstructing x-ray holographic images of living cells and automatic target recognition using Gabor Transforms for detecting strategic relocatable targets.

1986-1989 Thrust Area Leader (director of research and development) for Remote Sensing, Imaging and Signal Engineering (RISE) for the Engineering Directorate (including both the Electronics and Mechanical Engineering Departments). Proposed, sponsored, and directed R\&D projects. Responsible for the work of 20 engineers and $\$ 1.5 \mathrm{M} / \mathrm{yr}$.

1984-1988 Principal Investigator for Quantitative Nondestructive Evaluation Research, Engineering Research Division. Led projects in ultrasonic nondestructive evaluation of materials using advanced algorithms for system identification/deconvolution and image restoration to improve image resolution.

1984-1985 Technology Leader for Signal Processing, Nuclear Energy Systems Division, LLNL. Created and executed signal processing projects for the division, and supervised the work of a group of engineers.

1978-1984 Engineer, Engineering Research Division, Signal and Image Processing Research Group, Engineering Research Div. Conducted projects in modeling electromagnetic antennas and aircraft, adaptive filtering for seismic treaty verification, modeling a shock-hardened recorder for measuring acceleration in a missile warhead.

1977-1978 Doctoral student on leave from LLNL at the University of California, Santa Barbara.

1974-1977 Engineer, Engineering Research Division and Chemistry and Computations Systems Division. Worked on adaptive filters for chemistry experiments, modeling and reliability studies for nuclear safety systems.

Professional Activities and Memberships

Senior Member and Conference session chairman / organizer, IEEE (Institute of Electrical and Electronics Engineers). Member, Society of Exploration Geophysicists (SEG). 
Reviewer for IEEE Transactions on Signal Processing, Circuits and Systems and various other journals. HKN (Eta Kappa Nu), Electrical Engineering academic honorary society, and Sigma Xi, The Scientific Research Society.

Publications More than 125 technical publications, including one book chapter, journal papers, conference papers, and reports.

\section{Selected Publications of G. A. Clark}

M. E. Glinsky, G. A. Clark, Peter K.-Z. Cheng, K. R. Sandhya Devi, J., H. Robinson, and G. E. Ford, "Automatic Event Picking in Prestack Migrated Gathers Using a Probabilistic Neural Network," Geophysics, Vol. 66, No. 5 (SeptemberOctober, 2001), pp. 1488-1496.

G. A. Clark, S. K. Sengupta, W. D. Aimonetti, F. Roeske and J. G. Donetti, "Multispectral Image Feature Selection for Land Mine Detection," Lawrence Livermore National Laboratory report UCRL-JC-124375-Rev.1, IEEE Trans. Geoscience and Remote Sensing, January, 2000, pp. 304-311.

P. C. Schaich, G. A. Clark, K.-P. Ziock, S. K. Sengupta, “Automatic Image Analysis for Detecting and Quantifying Gamma-Ray Sources in Coded Aperture Images," IEEE Transactions on Nuclear Science, Vol. 43, No. 4, August, 1996..

G. A. Clark, S. K. Sengupta, W. D. Aimonetti, F. Roeske, J. G. Donetti, D. J. Fields, R. J. Sherwood, P. C. Schaich, "Multispectral Image Fusion for Detecting Land Mines," University of California report No. UCRL-JC-120319 Invited paper. SPIE's 1995 International Symposium on Aerospace/Defense Sensing and Dual-Use Photonics, Detection Technologies for Mines and Minelike Targets, Orlando, Florida, April 17-21, 1995.

G. A. Clark, Sailes K. Sengupta, W. D. Aimonetti, F. Roeske, J. G. Donetti, D. J. Fields, R. J. Sherwood, P. C. Schaich, "Land Mine Detection Using Multispectral Image Fusion," University of California report No. UCRL-JC-120710, Symposium on Autonomous Systems in Mine Countermeasures, U. S. Naval Postgraduate School, Monterey, CA, April 4-7, 1995.

P. C. Schaich, G. A. Clark, K.-P. Ziock, S. K. Sengupta, "Computer Vision for Detecting and Quantifying Gamma-Ray Sources in Coded Aperture Images," University of California report No. UCRL-JC-117476, Twenty-Eighth Asilomar Conference on Signals, Systems and Computers, Pacific Grove, CA, October 31-November 2, 1994.

G. A. Clark, S. K. Sengupta, M. R. Buhl, R. J. Sherwood, P. C. Schaich, N. Bull, R. J. Kane, and M. J. Barth, "Detecting Buried Objects by Fusing Dual-Band Infrared Images," Invited paper, Asilomar Conference on Signals, Systems and Computers, Pacific Grove, CA, Nov. 1-3, 1993.

G. A. Clark, S. K. Sengupta, P. C. Schaich, R. J. Sherwood, M. R. Buhl, J. E. Hernandez, D. J. Fields, and M. R. Carter, "Data Fusion for the Detection of Buried Land Mines," International Symposium on Substance Identification Technologies, European Optical Society (EOS)/The International Society for Optical Engineering (SPIE), Congress Centre Innsbruck, Innsbruck, Austria, October 4-8, 1993.

G. A. Clark, S. K. Sengupta, R. J. Sherwood, J. E. Hernandez, M. R. Buhl, P. C. Schaich, R. J. Kane, M. J. Barth, and N. K. DelGrande, "Sensor Feature Fusion for Detecting Buried Objects," Invited paper, SPIE's 1993 International Symposium and Exhibition on Optical Engineering and Photonics in Aerospace and Remote Sensing, Conference on Underground and Obscured Imaging and Detection, Orlando, Florida, April 12-16, 1993. 
G. A. Clark, "Report on the Workshop on Automatic Target Recognition (ATR) for Airborne Standoff Mine Detection (ASMD)," Sponsored by DARPA and the U. S. Marines at the System Planning Corporation, Arlington, VA (Workshop: December 9-10, 1992), March 5, 1993.

G. A. Clark (Workshop Chairman), J. E. Hernandez, S. K. Sengupta, R. J. Sherwood, M. R. Buhl, P. C. Schaich, R. J. Kane, M. J. Barth, and N. K. DelGrande, "Computer Vision and Sensor Fusion for Detecting Buried Mines," Workshop on Automatic Target Recognition (ATR) for Airborne Standoff Mine Detection (ASMD), Sponsored by DARPA and the U. S. Marines at the System Planning Corporation, Arlington, VA, December 9-10, 1992.

G. A. Clark, J. E. Hernandez, S. K. Sengupta, R. J. Sherwood, P. C. Schaich, M. R. Buhl, R. J. Kane, M. J. Barth, and N. K. DelGrande, "Computer Vision and Sensor Fusion for Detecting Buried Objects," Asilomar Conference on Signals, Systems and Computers, Pacific Grove, CA, October 26-28, 1992..

G. A. Clark, J. E. Hernandez, B. S. Lawver, and R. J. Sherwood, "Gabor Transforms and Neural Networks for Automatic Target Recognition," Workshop on Neural Networks: Academic/Industrial/NASA/Defense (WNN-AIND 91), Auburn University, Alabama, Lawrence Livermore National Laboratory document no. UCRL-JC-105362, Feb. 11-13, 1991.

G. A. Clark, J. E. Hernandez and Robert J. Sherwood, "Image Invariance Properties of Gabor Transforms and Neural Networks for Automatic Target Recognition," Neural Networks for Decision, Estimation, and Control Workshop, Naval Underwater Systems Center, Newport, R. 1., August 7 and 8, 1990.

D. B. Harris and G. A. Clark, "A Comparison of Spatial Averaging and Cadzow's Method for Array Wavenumber Estimation," Proceedings, Asilomar Conference on Signals, Systems and Computers, Pacific Grove, CA., Nov. 1, 1989, p. 792 .

G. A. Clark, "The Revelations of Acoustic Waves," Science and Technology Review, Lawrence Livermore National Laboratory, Lawrence Livermore National Laboratory report, UCRL-52000-99-5, U. S. Government Printing Office 1999/783-046-80013, May, 1999. 


\title{
Appendix:
}

\author{
Abstracts Obtained from the ISI Web of Knowledge, ISI Web of Science, Science \\ Citation Index (SCI Expanded). \\ $\mathbf{U R L}=\underline{\text { http: } / / \text { isi } 1 . \text { isiknowledge.com/portal.cgi/wos }}$
}

Search results (ISI) using "vehicle identification"

\section{A multimedia data mining framework: Mining information from traffic video sequences \\ Chen SC, Shyu ML, Zhang C, Strickrott J}

JOURNAL OF INTELLIGENT INFORMATION SYSTEMS

19 (1): 61-77 JUL 2002

Document

type: Article
Language: English

Cited

References: 22
Times

Cited: 0

\begin{abstract}
:
The analysis and mining of traffic video sequences to discover important but previously unknown knowledge such as vehicle identification, traffic flow, queue detection, incident detection, and the spatio-temporal relations of the vehicles at intersections, provide an economic approach for daily traffic monitoring operations. To meet such demands, a multimedia data mining framework is proposed in this paper. The proposed multimedia data mining framework analyzes the traffic video sequences using background subtraction, image/video segmentation, vehicle tracking, and modeling with the multimedia augmented transition network (MATN) model and multimedia input strings, in the domain of traffic monitoring over traffic intersections. The spatio-temporal relationships of the vehicle objects in each frame are discovered and accurately captured and modeled. Such an additional level of sophistication enabled by the proposed multimedia data mining framework in terms of spatio-temporal tracking generates a capability for automation. This capability alone can significantly influence and enhance current data processing and implementation strategies for several problems vis-a-vis traffic operations. Three real-life traffic video sequences obtained from different sources and with different weather conditions are used to illustrate the effectiveness and robustness of the proposed multimedia data mining framework by demonstrating how the proposed framework can be applied to traffic applications to answer the spatio-temporal queries.
\end{abstract}


Author Keywords:

multimedia data mining, spatio-temporal relationships, multimedia augmented transition network (MATN), vehicle tracking

KeyWords Plus:

TRACKING

Addresses:

Chen SC, Florida Int Univ, Sch Comp Sci, Distributed Multimedia Informat Syst Lab, Miami, FL 33199 USA

Florida Int Univ, Sch Comp Sci, Distributed Multimedia Informat Syst Lab, Miami, FL 33199 USA

Univ Miami, Dept Elect \& Comp Engn, Coral Gables, FL 33124 USA

Publisher:

KLUWER ACADEMIC PUBL, DORDRECHT

IDS Number:

$554 \mathrm{CE}$

ISSN:

0925-9902

Automated vehicle identification tag-matching algorithms for estimating vehicle travel times - Comparative assessment

Hellinga B

ARTIFICIAL INTELLIGENCE AND INTELLIGENT TRANSPORTATION SYSTEMS

TRANSPORTATION RESEARCH RECORD

(1774): 106-114 2001

Document

type: Article

Language: English

Cited

Times

References: $4 \quad$ Cited: 0

\section{Abstract:}

The computational complexity associated with three candidate automated vehicle identification (AVI) tag-matching algorithms that could be used to obtain individual vehicle travel time data in real time is examined. These algorithms are suitable for 
application to a linear roadway facility using transponder tags that do not have programmable memory. Analytical expressions are derived to estimate the worst-case and average computational load associated with each algorithm. A simulation is conducted to test the validity of the assumptions made in these derivations and to perform a sensitivity analysis on several key system parameters, including the rate of flow of AVI-equipped vehicles, the mean travel time between tag reader stations, the coefficient of variation of travel time, and the proportion of vehicles that pass the upstream tag readers.

\section{Addresses:}

Hellinga B, Univ Waterloo, Dept Civil Engn, Waterloo, ON N2L 361, Canada

Univ Waterloo, Dept Civil Engn, Waterloo, ON N2L 361, Canada

Publisher:

TRANSPORTATION RESEARCH BOARD NATL RESEARCH COUNCIL, WASHINGTON

IDS Number:

BU65B

ISSN:

Origin-destination matrices estimation model using automatic vehicle identification data and its application to the Han-Shin expressway network Asakura Y, Hato E, Kashiwadani M TRANSPORTATION 27 (4): 419-438 2000
Document type: Article
Cited Times References: $13 \quad$ Cited: 0

\section{Abstract:}

The Automatic Vehicle Identification (AVI) system was recently installed in expressway networks in Japan. License plate numbers of passing vehicles are monitored through roadside AVI cameras and then recognized. This paper shows the formulation of origin and destination (OD) matrices estimation model using the observed data with the AVI system. The results of license plate matching between a pair of AVI cameras are involved as the input variables. The formulated model is a least squares model and yields to the linear transformation of the partly observed OD matrices. The model is applied to the Kobe corridor line in the Han-Shin expressway network. It is found that the estimated 
OD matrix is consistent with the one using the previous mail survey. The proposed estimation method is expected to investigate the day-to-day fluctuations of OD patterns in the expressway network.

Author Keywords:

automatic vehicle identification, OD estimation, urban expressway

KeyWords Plus:

TRAFFIC COUNTS, FLOWS

Addresses:

Asakura Y, Ehime Univ, Dept Civil \& Environm Engn, Matsuyama, Ehime

7908577, Japan

Ehime Univ, Dept Civil \& Environm Engn, Matsuyama, Ehime 7908577, Japan

Publisher:

KLUWER ACADEMIC PUBL, DORDRECHT

IDS Number:

$357 \mathrm{MD}$

ISSN:

$0049-4488$

\title{
Vector quantization for license-plate location and image coding Zunino R, Rovetta S \\ IEEE TRANSACTIONS ON INDUSTRIAL ELECTRONICS \\ 47 (1): 159-167 FEB 2000
}
Document
type: Article
Language: English
Cited
Times
References: $35 \quad$ Cited: 0

\begin{abstract}
:
License-plate location in sensor images plays an important role in vehicle identification for automated transport systems (ATS's). This paper presents a novel method based on vector quantization (VQ) to process vehicle images. The proposed method makes it possible to perform superior picture compression for archival purposes and to support effective location at the same time. As compared,vith classical approaches, VQ encoding can give some hints about the contents of image regions; such additional information can be exploited to boost location performance. The VQ system can be trained by way of
\end{abstract}


examples; this gives the advantages of adaptiveness and on-field tuning. The approach has been tested in a real industrial application and included satisfactorily in a complete ATS for vehicle identification.

Author Keywords:

image analysis, image coding, road vehicle identification, vector quantization

KeyWords Plus:

NEURAL-NETWORK, KOHONEN MAP, ALGORITHM, COMPRESSION, RECOGNITION

Addresses:

Zunino R, Univ Genoa, Dept Biophys \& Elect Engn, Via Opera Pia 11A, I-16145

Genoa, Italy

Univ Genoa, Dept Biophys \& Elect Engn', I-16145 Genoa, Italy

Publisher:

IEEE-INST ELECTRICAL ELECTRONICS ENGINEERS INC, NEW YORK

IDS Number:

283WF

ISSN:

0278-0046

SYNTACTIC PATTERN RECOGNIZER FOR VEHICLE IDENTIFICATION

NUMBERS

COWELL JR

IMAGE AND VISION COMPUTING

13 (1): 13-19 FEB 1995

Document

type: Article

Language: English $\frac{\text { Cited }}{\underline{\text { References: } 27} \quad \underline{\text { Times }}} \underline{\underline{\text { Cited:2 }}}$

\section{Abstract:}

Road pricing is certain to be introduced in most cities by the year 2000. Most systems require vehicles to carry a transducer which identifies it. If this fails, the only way of identifying the vehicle is by reading the vehicle identification numbers (VIN). A recognition system is described which thins the characters using conventional algorithms 
to produce 8-connected skeletons and uses a new pattern grammer to describe these characters in terms of simple string. The same string represents a character irrespective of its position, size or orientation. The characters used to test the performance of the algorithm were extracted from a wide variety of images of vehicles. They are not idealized representations. The origin of these characters means that they are very varied in their size, orientation and completeness. No normalisation of characters is required prior to determining their representation in the pattern grammar described.

Author Keywords:

SYNTACTIC PATTERN RECOGNITION, GRAPH GRAMMARS, VIN

Addresses:

COWELL JR, DE MONTFORT UNIV MILTON KEYNES,KENTS

HILL,HAMMERWOOD GATE,MILTON KEYNES MK7 6HP,ENGLAND

Publisher:

BUTTERWORTH-HEINEMANN LTD, OXFORD

IDS Number:

QE995

ISSN:

$0262-8856$

Video Johnson-like criterion for moving vehicle identification Szu H, Cox P

JOURNAL OF ELECTRONIC IMAGING

7 (4): 781-784 OCT 1998
Document
type: Article
Language: English
Cited
References: 6
$\underline{\text { Times }}$
Cited: 1

\begin{abstract}
:
A wavelet, being a bank of matched filters at a constant fidelity, is appropriate for low bandwidth video communication-compression and is also proposed here to test the video contrast sensitivity surface. This generalization permits us to evaluate the trade-off between the spatial redundancy verses temporal redundancy reductions. This paper addresses the relationship between very low bandwidth video compression and human perception for target discrimination using video. (C) 1998 SPIE and IS\&T. [S10179909(98)01104-0].
\end{abstract}


KeyWords Plus:

COMPRESSION

Addresses:

Szu H, USN, Ctr Surface Warfare, Dahlgren Div, Dahlgren, VA 22446 USA

USN, Ctr Surface Warfare, Dahlgren Div, Dahlgren, VA 22446 USA

Trident Syst Inc, Fairfax, VA 22030 USA

Publisher:

I S \& T - SOC IMAGING SCIENCE TECHNOLOGY, SPRINGFIELD

IDS Number:

280LC

ISSN:

1017-9909

\section{MONITORING FREEWAY TRAFFIC CONDITIONS WITH AUTOMATIC}

VEHICLE IDENTIFICATION SYSTEMS

LEVINE SZ, MCCASLAND WR

ITE JOURNAL-INSTITUTE OF TRANSPORTATION ENGINEERS

64 (3): 23-28 MAR 1994

Document

type: Article

Language: English

Cited

Times

References: 0

Cited: 2

Addresses:

LEVINE SZ, TEXAS DEPT TRANSPORTAT,HOUSTON,TX

Publisher:

INST TRANSPORTATION ENGINEERS, WASHINGTON

IDS Number:

$\mathrm{NC} 803$

ISSN:

0162-8178 


\title{
THE HEAVY VEHICLE ELECTRONIC LICENSE PLATE PROGRAM AND CRESCENT DEMONSTRATION PROJECT
} WALTON CM

IEEE TRANSACTIONS ON VEHICULAR TECHNOLOGY 40 (1): 147-151 Part 1 FEB 1991

\section{Document}

type: Article

Language: English

Cited

Times

\begin{abstract}
:
The Heavy Vehicle Electronic License Plate (HELP) Program and Crescent Demonstration Project is a binational, multistate cooperative study and demonstration project involving government and industry participating to investigate new technologies that have the potential to provide an integrated heavy vehicle management system with applications to both highway and vehicle systems. This initiative has been described as a leading example of the Intelligent Vehicle Highway System initiative focusing on commercial vehicle operations (CVO). The study elements of this project focus on five technologies that can be integrated into a heavy vehicle management system: 1) automatic vehicle identification (AVI), 2) weigh-in-motion (WIM), 3) automatic vehicle classification (AVC), 4) satellite data links, and 5) data communication networks including on-board computers. The program, initiated approximately seven years ago, consists of three phases, which include assessing the feasibility of the concept, technical studies involving laboratory and field tests, and, lastly, the demonstration phase. Perhaps the most significant of the activities to be derived from this project to date are those focusing on institutional arrangements afforded by the emerging technology in this experiment. The demonstration element of the program, referred to as the Crescent Demonstration Project, began in April 1990 involving six states within the United States and one providence of Canada and will be phased into a full-scale operation over the next three years. It is estimated that over the life of the program and the project, more than $\$ 20$ million will be expended or contributed by both industry and government in testing this landmark program. This paper provides an overview of the program and the components of the implementation plan.
\end{abstract}

Addresses:

WALTON CM, UNIV TEXAS,DEPT CIVIL ENGN,AUSTIN,TX 78712

\section{Publisher:}

IEEE-INST ELECTRICAL ELECTRONICS ENGINEERS INC, NEW YORK

\section{IDS Number:}

EZ729 
ISSN:

0018-9545

HYPER-PIGMENTATION IN THE LONG BONES OF THE LOWER-LIMBS AS

A BASIS FOR VEHICLE IDENTIFICATION AND TRAFFIC ACCIDENT

RECONSTRUCTION

LISOWSKI Z, MAREK Z

FORENSIC SCIENCE INTERNATIONAL

20 (3): 251-255 1982

Document

type: Article

Language: English

Cited

References: 0

Times

Cited: 1

\section{Addresses:}

LISOWSKI Z, NICHOLAS COPERNICUS MED ACAD,INST FORENS

MED,CRACOW UL GRZEGORZECKA 16,PL-31531 CRACOW,POLAND

Publisher:

ELSEVIER SCI IRELAND LTD, CLARE

IDS Number:

$\mathrm{PH} 494$

ISSN:

0379-0738

AUTOMATIC VEHICLE IDENTIFICATION - TESTS AND APPLICATIONS IN

THE LATE 1970S

FOOTE RS

IEEE TRANSACTIONS ON VEHICULAR TECHNOLOGY

29 (2): 226-229 1980

Document

type: Article

Language: English

Cited

Times

References: 0

Cited: 0

Addresses:

FOOTE RS, PORT AUTHOR NEW YORK \& NEW JERSEY,1 WORLD TRADE CTR,ROOM 56 N,NEW YORK,NY 10048

Publisher:

IEEE-INST ELECTRICAL ELECTRONICS ENGINEERS INC, NEW YORK 
IDS Number:

JV075

ISSN:

0018-9545

MICROWAVE AUTOMATIC VEHICLE IDENTIFICATION (AVI) SYSTEM

SAKURAGI J, KIMURA Y, KAMEDA K, KAMATA S IEEE TRANSACTIONS ON VEHICULAR TECHNOLOGY 28 (3): 228-228 1979

Document type: Meeting Abstract

Language: English

Cited

Times

References: $0 \quad$ Cited: 0

Addresses:

TOSHIBA CORP,TOKYO,JAPAN

Publisher:

IEEE-INST ELECTRICAL ELECTRONICS ENGINEERS INC, NEW YORK

IDS Number:

HF991

ISSN:

0018-9545

\section{PROMISE OF AUTOMATIC VEHICLE IDENTIFICATION HAUSLEN RA \\ IEEE TRANSACTIONS ON VEHICULAR TECHNOLOGY 26 (1): 30-38 1977}

Document type: Article

Language: English $\frac{\text { Cited }}{\underline{\text { References: } 8} \quad \underline{\text { Times }}} \underline{\underline{\text { Cited: } 1}}$

Addresses:

PORT AUTHOR NEW YORK \& NEW JERSEY,NEW YORK,NY 10048

Publisher:

IEEE-INST ELECTRICAL ELECTRONICS ENGINEERS INC, NEW YORK 
IDS Number:

CT683

ISSN:

0018-9545

MICROWAVE AUTOMATIC VEHICLE IDENTIFICATION (MAVI) SYSTEM CONSTANT JN

IEEE TRANSACTIONS ON VEHICULAR TECHNOLOGY

VT23 (2): 44-54 1974

Document

type: Article

Language: English $\frac{\text { Cited }}{\underline{\text { References: } 88} \quad \underline{\text { Times }}} \underline{\underline{\text { Cited: } 1}}$

Addresses:

RCS ASSOC INC,CLAREMONT,CA 91711

Publisher:

IEEE-INST ELECTRICAL ELECTRONICS ENGINEERS INC, NEW YORK

IDS Number:

U1303

ISSN:

0018-9545

MICROWAVE AUTOMATIC VEHICLE IDENTIFICATION SYSTEM

KLENSCH RJ, ROSEN J, STARAS H

RCA REVIEW

34 (4): 566-579 1973

Document

type: Article

Language: English

Cited

Times

References: $4 \quad$ Cited: 1

Addresses:

RCA LABS,PRINCETON,NJ 08540

Publisher:

RCA CORPORATION, PRINCETON 
IDS Number:

$S 2241$

ISSN:

0033-6831

Search results (ISI) using "license plate reading"

Drive by motor vehicle emissions: Immediate feedback in reducing air pollution Bishop GA, Stedman DH, Hutton RB, Bohren L, Lacey N

ENVIRONMENTAL SCIENCE \& TECHNOLOGY

34 (6): 1110-1116 MAR 152000

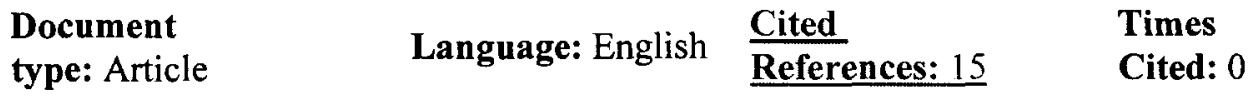

\begin{abstract}
:
Using input from the public, a new type of vehicle emissions information system has been developed which utilizes an innovative variable message sign to display individual vehicle emissions information to passing drivers. Called the Smart Sign, the system merged highway messaging and on-road vehicle emissions sensing into a cost-effective public information system. The Smart Sign used a combination of words, colors, and graphics to connect with its audience. During its operational test period the system proved to be a viable technical concept which can be operated dependably and safely in even high traffic areas (in excess of 1000 vehicles per hour). The system was subjected to a wide range of operating conditions including weather extremes $(-20$ to 100 degrees $F$, heavy rain, hail, snow) and between May 16, 1996 to May 15, 1997 recorded unattended emissions information of more than 3 million readings from an estimated 250000 individuals. The ability to operate the system without constant human supervision has created a cost-effective messaging system capable of delivering real-time vehicle emissions information for a long term estimated cost of $\$ 60000 / \mathrm{yr}$ or about $\$ 0.02$ per test and demonstrated the potential for intelligent highways of the future to detect gross polluting vehicles. Using information from a companion license plate reading system a sample of 474 motorists ( $14 \%$ poor, $43 \%$ fair, and $43 \%$ good) were interviewed by telephone. Seventy-six percent of the weighted population had a favorable impression ( $5 \%$ unfavorable) of the Smart Sign with the majority (61\%) expressing its informative nature as the main reason. Eight percent of the total sample planned to do something in response to the sign. Respondents in the "POOR" stratum (31\%) were almost twice as likely to respond to the system as those in the "FAIR" stratum (16\%) and five times as likely as those in the "GOOD" stratum (6\%). Sixteen percent of the poor's $(1.6 \%$ of the overall fleet) reported to have already taken corrective action as a result of the Smart
\end{abstract}


Sign. This produces an estimate that more than 4000 voluntary repairs were made as a result of Smart Sign readings during the year.

KeyWords Plus:

PROGRAM, INSPECTION

Addresses:

Bishop GA, Univ Denver, Dept Chem \& Biochem, Denver, CO 80208 USA

Univ Denver, Dept Chem \& Biochem, Denver, CO 80208 USA

Univ Denver, Dept Mkt, Denver, CO 80208 USA

Colorado State Univ, Natl Ctr Vehicle Emiss Control \& Safety, Ft Collins, CO

80523 USA

Colorado Dept Transportat, Denver, CO 80222 USA

Publisher:

AMER CHEMICAL SOC, WASHINGTON

IDS Number:

293RR

ISSN:

0013-936X

$* * * * * * * * * * * * *$ Key Paper $* * * * * * * * * * * * * *$

Apparently, only the abstract is available online (GAC). I tried accessing the paper, and the "Full Record" contained only the abstract.

Specifications for automated license plate reading equipment for transportation planning

French LJ, Martinelli DR, Eck RW, Pascoli J

PROGRESS IN TRANSPORTATION DATA 1998

TRANSPORTATION RESEARCH RECORD (1625): 50-56 1998

Document

type: Article

$\begin{array}{lll}\text { Language: English } & \text { Cited } & \text { Times } \\ & \underline{\text { References: } 5} & \text { Cited: } 0\end{array}$ 


\begin{abstract}
:
Recent technological advances in computer hardware, software, and image processing have led to the development of an automated license plate reader (ALPR). This equipment was developed primarily for enforcement and security applications, such as monitoring parking garages or border crossings. Because license plate data are used in several transportation planning studies, ALPRs have the potential to increase the quality and efficiency of many typical activities of transportation planning agencies. The key performance attributes of an ALPR with respect to the specific needs of transportation planning are determined. The following general needs are investigated: (a) the specific license plate data requirements of transportation planning studies; (b) the effect of the equipment on traffic operations and safety; and (c) special equip ment characteristics required because of the temporary nature of transportation planning and the constraints of transportation planning agencies. Tn addition, an existing ALPR was tested in situations likely to be encountered in transportation planning applications. Technical specifications for an ALPR for transportation planning are developed. These specifications can be used to provide motivation and direction for the future development of an ALPR for transportation planning. Finally, the technical challenges to developing the ALPR are discussed.
\end{abstract}

Addresses:

French LJ, W Virginia Univ, Dept Civil \& Environm Engn, Natl Transportat Ctr, POB 6103, Morgantown, WV 26506 USA

W Virginia Univ, Dept Civil \& Environm Engn, Natl Transportat Ctr, Morgantown, WV 26506 USA

W Virginia Dept Transportat, Div Highways Planning Div, Charleston, WV 25304 USA

Publisher:

NATL ACAD SCI, WASHINGTON

IDS Number:

BN48A

ISSN:

0361-1981

A MINIATURIZED SPACE-VARIANT ACTIVE VISION SYSTEM - CORTEX-I BEDERSON BB, WALLACE RS, SCHWARTZ E

MACHINE VISION AND APPLICATIONS 


\title{
Document
}

type: Article

Language: English

Cited

Times

References: 33

Cited: 1

\begin{abstract}
:
We have developed a prototype for a miniaturized, active vision system with a sensor architecture based on a logarithmically structured, space-variant, pixel geometry. The central part of the image has a high resolution, and the periphery has a a smoothly falling resolution. The human visual system uses a similar image architecture. Our system integrates a miniature CCD-based camera, a novel pan-tilt actuator/controller, general purpose processors, a video-telephone modem and a display. Due to the ability of spacevariant sensors to cover large work spaces, yet provide high acuity with an extremely small number of pixels, architectures with space-variant, active vision systems provide a potential for reductions in system size and cost of several orders of magnitude. Cortex-I takes up less than a third of a cubic foot, including camera, actuators, control, computers, and power supply, and was built for a (one-off) parts cost of roughly US $\$ 2000$. In this paper, we describe several applications that we have developed for Cortex-I such as tracking moving objects, visual attention, pattern recognition (license plate reading), and video-telephone communications (teleoperation). We report here on the design of the camera and optics $(8 \times 8 \times 8 \mathrm{~mm}$ ), a method to convert the uniform image to a spacevariant image, and a new miniature pan-tilt actuator, the spherical pointing motor (SPM), $(4 \times 5 \times 6 \mathrm{~cm})$. Finally, we discuss applications for motion tracking and license plate reading. Potential application domains for systems of this type include vision systems for mobile robots and robot manipulators, traffic monitoring systems, security and surveillance, telerobotics, and consumer video communications. The long-range goal of this project is to demonstrate that major new applications of robotics will become feasible when small, low-cost, machine-vision systems can be mass produced. We use the term "commodity robotics" to express the expected impact of the possibilities for opening up new application niches in robotics and machine vision, for what has until now been an expensive, and therefore limited, technology.
\end{abstract}

\section{Author Keywords:}

CORTEX-I, ACTIVE VISION SYSTEM, MINIATURE, SPACE-VARIANT

SENSORS, SPHERICAL POINTING MOTOR

KeyWords Plus:

PERCEPTION

Addresses:

BEDERSON BB, UNIV NEW MEXICO,DEPT COMP SCI,ALBUQUERQUE,NM

87131 
NYU,COURANT INST MATH SCI,NEW YORK,NY 10012

BOSTON UNIV,DEPT COGNIT \& NEURAL SYST,BOSTON,MA 02146

Publisher:

SPRINGER VERLAG, NEW YORK

IDS Number:

QR698

ISSN:

0932-8092

Real-time multiple vehicle detection and tracking from a moving vehicle

Betke M, Haritaoglu E, Davis LS

MACHINE VISION AND APPLICATIONS

12 (2): 69-83 SEP 2000

\section{Document}

type: Article
Language: English

Cited

References: 62
Times

Cited: 2

\begin{abstract}
:
A real-time vision system has been developed that analyzes color videos taken from a forward-looking video camera in a car driving on a highway. The system uses a combination of color, edge, and motion information to recognize and track the road boundaries, lane markings and other vehicles on the road. Cars are recognized by matching templates that are cropped from the input data online and by detecting highway scene features and evaluating how they relate to each other. Cars are also detected by temporal differencing and by tracking motion parameters that are typical for cars. The system recognizes and tracks road boundaries and lane markings using a recursive leastsquares filter. Experimental results demonstrate robust, real-time car detection and tracking over thousands of image frames. The data includes video taken under difficult visibility conditions.

\section{Author Keywords:}

real-time computer vision, vehicle detection and tracking, object recognition under ego-motion, intelligent vehicles

KeyWords Plus:

VISION SYSTEM, ROAD, PARALLEL
\end{abstract}




\title{
Addresses:
}

Betke M, Boston Coll, Dept Comp Sci, Chestnut Hill, MA 02167 USA

Boston Coll, Dept Comp Sci, Chestnut Hill, MA 02167 USA

Univ Maryland, College Pk, MD 20742 USA

Publisher:

SPRINGER-VERLAG, NEW YORK

IDS Number:

$354 \mathrm{HX}$

ISSN:

0932-8092

\section{A MINIATURIZED SPACE-VARIANT ACTIVE VISION SYSTEM - CORTEX-I BEDERSON BB, WALLACE RS, SCHWARTZ E MACHINE VISION AND APPLICATIONS 8 (2): 101-109 1995}
Document
type: Article
Language: English
Cited
Times
References: 33
Cited: 1

\begin{abstract}
:
We have developed a prototype for a miniaturized, active vision system with a sensor architecture based on a logarithmically structured, space-variant, pixel geometry. The central part of the image has a high resolution, and the periphery has a a smoothly falling resolution. The human visual system uses a similar image architecture. Our system integrates a miniature CCD-based camera, a novel pan-tilt actuator/controller, general purpose processors, a video-telephone modem and a display. Due to the ability of spacevariant sensors to cover large work spaces, yet provide high acuity with an extremely small number of pixels, architectures with space-variant, active vision systems provide a potential for reductions in system size and cost of several orders of magnitude. Cortex-I takes up less than a third of a cubic foot, including camera, actuators, control, computers, and power supply, and was built for a (one-off) parts cost of roughly US $\$ 2000$. In this paper, we describe several applications that we have developed for Cortex-I such as tracking moving objects, visual attention, pattern recognition (license plate reading), and video-telephone communications (teleoperation). We report here on the design of the camera and optics ( $8 \times 8 \times 8 \mathrm{~mm}$ ), a method to convert the uniform image to a spacevariant image, and a new miniature pan-tilt actuator, the spherical pointing motor (SPM), $(4 \times 5 \times 6 \mathrm{~cm})$. Finally, we discuss applications for motion tracking and license plate
\end{abstract}


reading. Potential application domains for systems of this type include vision systems for mobile robots and robot manipulators, traffic monitoring systems, security and surveillance, telerobotics, and consumer video communications. The long-range goal of this project is to demonstrate that major new applications of robotics will become feasible when small, low-cost, machine-vision systems can be mass produced. We use the term "commodity robotics" to express the expected impact of the possibilities for opening up new application niches in robotics and machine vision, for what has until now been an expensive, and therefore limited, technology.

Author Keywords:

CORTEX-I, ACTIVE VISION SYSTEM, MINIATURE, SPACE-VARIANT

SENSORS, SPHERICAL POINTING MOTOR

KeyWords Plus:

PERCEPTION

Addresses:

BEDERSON BB, UNIV NEW MEXICO,DEPT COMP SCI,ALBUQUERQUE,NM

87131

NYU,COURANT INST MATH SCI,NEW YORK,NY 10012

BOSTON UNIV,DEPT COGNIT \& NEURAL SYST,BOSTON,MA 02146

Publisher:

SPRINGER VERLAG, NEW YORK

IDS Number:

QR698

ISSN:

0932-8092

Real-time multiple vehicle detection and tracking from a moving vehicle Betke M, Haritaoglu E, Davis LS MACHINE VISION AND APPLICATIONS

12 (2): 69-83 SEP 2000

Document

type: Article

Language: English

Cited

Times

References: 62

Cited: 2

Abstract: 
A real-time vision system has been developed that analyzes color videos taken from a forward-looking video camera in a car driving on a highway. The system uses a combination of color, edge, and motion information to recognize and track the road boundaries, lane markings and other vehicles on the road. Cars are recognized by matching templates that are cropped from the input data online and by detecting highway scene features and evaluating how they relate to each other. Cars are also detected by temporal differencing and by tracking motion parameters that are typical for cars. The system recognizes and tracks road boundaries and lane markings using a recursive leastsquares filter. Experimental results demonstrate robust, real-time car detection and tracking over thousands of image frames. The data includes video taken under difficult visibility conditions.

\section{Author Keywords:}

real-time computer vision, vehicle detection and tracking, object recognition

under ego-motion, intelligent vehicles

KeyWords Plus:

VISION SYSTEM, ROAD, PARALLEL

Addresses:

Betke M, Boston Coll, Dept Comp Sci, Chestnut Hill, MA 02167 USA

Boston Coll, Dept Comp Sci, Chestnut Hill, MA 02167 USA

Univ Maryland, College Pk, MD 20742 USA

Publisher:

SPRINGER-VERLAG, NEW YORK

IDS Number:

$354 \mathrm{HX}$

ISSN:

0932-8092

Performance analysis of a simple vehicle detection algorithm

Moon H, Chellappa R, Rosenfeld A

IMAGE AND VISION COMPUTING

20 (1): 1-13 JAN 12002

Document

type: Article
Language: English
Cited

References: 17
Times

Cited: 0 


\begin{abstract}
:
We have performed an end-to-end analysis of a simple model-based vehicle detection algorithm for aerial parking lot images. We constructed a vehicle detection operator by combining four elongated edge operators designed to collect edge responses from the sides of a vehicle. We derived the detection and localization performance of this algorithm, and verified them by experiments. Performance degradation due to different camera angles and illuminations was also examined using simulated images. Another important aspect of performance characterization - whether and how much prior information about the scene improves performance - was also investigated. As a statistical diagnostic tool for the detection performance, a computational approach employing bootstrap was used. (C) 2002 Elsevier Science B.V. All rights reserved.
\end{abstract}

\title{
Author Keywords:
}

performance analysis, vehicle detection, aerial image, bootstrap, empirical

evaluation

Addresses:

Moon H, Univ Maryland, Ctr Automat Res, College Pk, MD 20742 USA

Univ Maryland, Ctr Automat Res, College Pk, MD 20742 USA

Publisher:

ELSEVIER SCIENCE BV, AMSTERDAM

IDS Number:

$518 \mathrm{NW}$

ISSN:

0262-8856

Results of ISI search using: "Vehicle Recognition"

$<$ My Rating $=\mathrm{A}>$ 
Recognizing vehicles in infrared images using IMAP parallel vision board Kagesawa M, Ueno S, Ikeuchi K, Kashiwagi H

\title{
IEEE TRANSACTIONS ON INTELLIGENT TRANSPORTATION
}

SYSTEMS

2 (1): 10-17 MAR 2001

Document type: Article

Language: English

Cited References: 16

Times Cited: 0

\begin{abstract}
:
This paper describes a method for vehicle recognition, in particular, for recognizing a vehicle's make and model. Our system is designed to take into account the fact that vehicles of the same make and model number come in different colors, to deal with this problem, our system employs infrared images, thereby eliminating color differences. Another reason for the use of infrared images is that it enables us to use the same algorithm both day and night. This ability is particularly important because the algorithm must be able to locate many feature points, especially at night. Our algorithm is based on a configuration of local features. For the algorithm, our system first makes a compressed database of local features of a target vehicle from training images given in advance; the system then matches a set of local features in the input image with those in the training images for recognition. This method has the following three advantages: 1) it can detect even if part of the target vehicle is occluded; 2) it can detect even if the target vehicle is translated due to running out of the lanes; and 3) it does not require us to segment a vehicle part from input images. We have two implementations of the algorithm. One is referred to as the
\end{abstract}


eigenwindow method, while the other is called the vector-quantization method. The former method is good at recognition, but is not very

fast. The latter method is not very good at recognition but it is suitable for an IMAP parallel image-processing board; hence, it can be fast.

In both implementations, the above-mentioned advantages have been confirmed by performing outdoor experiments.

Author Keywords:

infrared image, parallel image processor, vehicle recognition

KeyWords Plus:

OBJECTS

Addresses:

Kagesawa M, Univ Tokyo, Tokyo 1068558, Japan

Univ Tokyo, Tokyo 1068558, Japan

Publisher:

IEEE-INST ELECTRICAL ELECTRONICS ENGINEERS INC, NEW YORK

IDS Number:

$529 \mathrm{GV}$

ISSN:

1524-9050

Assessing the computational effort for structural 3D vehicle recognition Michaelsen E, Stilla U

ADVANCES IN PATTERN RECOGNITION

LECTURE NOTES IN COMPUTER SCIENCE 
1876: $357-3662000$

Document type: Article

Language: English

Cited References: 17

Times Cited: 0

\begin{abstract}
:
A model based structural recognition approach is used for 3D detection and localization of vehicles. It is theoretically founded by syntactic

pattern recognition using coordinate grammars and depicted by production nets. The computational effort significantly depends on certain

tolerance parameters and the distribution of input data in the attribute domain. A brief theoretical survey of these interrelations is

accompanied by comparing the performance on synthetic random data to the performance on data from different natural environments.
\end{abstract}

KeyWords Plus:

OBJECT RECOGNITION

Addresses:

Michaelsen E, FOM, FGAN, Res Inst Optron \& Pattern Recognit, Gutleuthausstr 1, D76275 Ettlingen, Germany

FOM, FGAN, Res Inst Optron \& Pattern Recognit, D-76275 Ettlingen, Germany

Publisher:

SPRINGER-VERLAG BERLIN, BERLIN

IDS Number:

BS80F 
ISSN:

0302-9743

$<$ My Rating $=\mathrm{A}>$

Real-time vehicle recognition using local feature extraction

Hwang W, Ko H

ELECTRONICS LETTERS

37 (7): 424-425 MAR 292001

Document type: Article

Language: English

Cited References: 4

Times Cited: 0

Abstract:

A novel feature extraction method based on local textures of image for real-time vehicle recognition tasks is proposed. In particular.

feature vectors are extracted from judicious combinations of partitioning and overlapping image blocks with a view to reducing cardinality

while retaining sufficient feature information for effective recognition. Experimental results are presented that show a reduction in

computational load of $80 \%$ and robustness to illumination and noise can be achieved.

KeyWords Plus:

OBJECTS

Addresses: 
Hwang W, Korea Univ, Dept Elect Engn, Sungbuk Ku, Seoul 136701, South Korea

Korea Univ, Dept Elect Engn, Sungbuk Ku, Seoul 136701, South Korea

Publisher:

IEE-INST ELEC ENG, HERTFORD

IDS Number:

421GG

ISSN:

0013-5194

$<$ My Rating $=\mathrm{A}>$

An approach to vehicle recognition using supervised learning

Kato T, Ninomiya $Y$

IEICE TRANSACTIONS ON INFORMATION AND SYSTEMS

E83D (7): 1475-1479 JUL 2000

Document type: Article

Language: English

Cited References: 9

Times Cited: 0

\footnotetext{
Abstract:

To enhance safety and traffic efficiency, a driver assistance system and an autonomous vehicle system are being developed. A preceding vehicle recognition method is important to develop such systems. In this paper, a visionbased preceding vehicle recognition method,
} 
based on supervised learning from sample images is proposed. The improvement for Modified Quadratic Discriminant Function (MQDF)

classifier that is used in the proposed method is also shown. And in the case of road environment recognition including the preceding vehicle recognition, many researches have been reported. However in those researches, a quantitative evaluation with large number of images has rarely been done. Whereas, in this paper, over 1,000 sample images for passenger vehicles, which are recorded on a highway during daytime, are used for an evaluation. The evaluation result shows that the performance in a low order case is improved from the ordinary MQDF. Accordingly, the calculation time is reduced more than $20 \%$ by using the proposed method. And the feasibility of the proposed method is also proved, due to the result that the proposed method indicates over $98 \%$ as classification rate.

Author Keywords:

vehicle recognition, supervised learning, MQDF, quantitative evaluation

Addresses:

Kato T, MIT, ITS Res Ctr, Cambridge, MA 02139 USA

Toyota Cent Res \& Dev Labs Inc, Aichi 4801192, Japan

Publisher:

IEICE-INST ELECTRONICS INFORMATION COMMUNICATIONS ENG, TOKYO

IDS Number:

339EG

ISSN:

0916-8532 
Vehicle recognition and tracking from road image sequences

Foresti GL, Murino V, Regazzoni C

IEEE TRANSACTIONS ON VEHICULAR TECHNOLOGY

48 (1): 301-318 JAN 1999

Document type: Article

Language: English

Cited References: 23

Times Cited: 1

\begin{abstract}
:
In this paper, synergies between the recognition and tracking processes for autonomous vehicle driving are studied. Object recognition is periodically performed to focus attention on specific parts of the visual signal and to assign them symbolic meanings. Tracking is used to

maintain correspondences between objects identified at successive recognition instants as well as to provide further features (e,g,,

spatio-temporal trajectories) on which to base object-pose estimation. Results obtained by using complex road scenes are reported,

which demonstrate the validity of the approach in terms of robustness, accuracy, and time responses.
\end{abstract}

Addresses:

Foresti GL, Univ Udine, Dept Math \& Comp Sci, I-33100 Udine, Italy

Univ Udine, Dept Math \& Comp Sci, I-33100 Udine, Italy

Univ Genoa, Dept Biophys \& Elect Engn, I-16145 Genoa, Italy

Publisher:

IEEE-INST ELECTRICAL ELECTRONICS ENGINEERS INC, NEW YORK 
IDS Number:

160BL

ISSN:

0018-9545

Vehicle recognition in infrared images using shared weight neural networks

de Ridder D, Schutte K, Schwering P

OPTICAL ENGINEERING

37 (3): 847-857 MAR 1998

Document type: Article

Language: English

Cited References: 16

Times Cited: 2

\begin{abstract}
:
The possibility of using certain kinds of neural networks, shared weight neural networks, to recognize vehicles in IR images is investigated.

We use the neural network as a preprocessor to find tank wheels in the images, followed by a more specific traditional search in the region(s) of interest found by the network; i.e., the neural network is used as a feature detector. In this way, although we train the networks on individual samples, we use the trained networks as nonlinear filters on entire images. The resulting system is tested on scale dependency and sensitivity to clutter in the background of images and performs adequately. (C) 1998 Society of Photo-Optical Instrumentation Engineers. [S0091-3286(98)01703-6].
\end{abstract}


Author Keywords:

automatic target recognition, shared weight neural networks, radial basis functions

KeyWords Plus:

AUTOMATIC TARGET RECOGNITION

Addresses:

de Ridder D, Delft Univ Technol, Fac Appl Phys, Pattern Recognit Grp, Lorentzweg 1, NL-2628 CJ Delft, Netherlands

Delft Univ Technol, Fac Appl Phys, Pattern Recognit Grp, NL-2628 CJ Delft,

Netherlands

TNO, Phys \& Elect Lab, Electroopt Grp, NL-2509 JG The Hague, Netherlands

Publisher:

SPIE - INTERNATIONAL SOCIETY FOR OPTICAL ENGINEERING, BELLINGHAM

IDS Number:

ZC007

ISSN:

$0091-3286$

\author{
A METHOD OF MOTION ANALYSIS USING SPATIOTEMPORAL IMAGE- \\ DIRECTIONAL TEMPORAL PLANE \\ TRANSFORM \\ TANIGUCHI H, SEKI A, KURODA S, IKEBATA S, FURUSAWA H \\ SYSTEMS AND COMPUTERS IN JAPAN \\ 26 (7): 88-97 JUL 1995
}


Document type: Article

Language: English

Cited References: 9

Times Cited: 0

Abstract:

Some of the recent image processing methods proposed for detecting object moving in 3-

D space form a spatiotemporal image by

placing consecutive camera images side by side in temporal order. This paper presents

one such method, the directional temporal plane

transform method (DTT), an image processing method that is not influenced by

environmental changes. Assuming that the objects are

moving on a nearly constant path, DTT first extracts significant data about these objects

from each image, and then makes a 1-D data

stream by projecting the data long a directional axis parallel to the moving loci. After

that, by placing the 1-D data from individual frames

side by side in temporal order, the spatiotemporal image is transformed into a 2-D image

on a directional temporal plane. Since the object

motion is represented by regions of this 2-D image, moving objects can be detected by

simple 2-D image processing. This method was

used on an experimental basis to detect vehicles running along a road. Experimental

results show the effectiveness of the method. An

advantage of this method is its ability to detect vehicles using the same processing during

both daytime and nighttime-a feature that has not

been achieved with conventional methods.

Author Keywords:

IMAGE PROCESSING, SPATIOTEMPORAL IMAGE, RECOGNITION OF MOVING

OBJECTS, VEHICLE 
RECOGNITION, TRAFFIC FLOW MEASUREMENT

Addresses:

TANIGUCHI H, MITSUBISHI ELECTR CORP,IND ELECTR \& SYST

LAB,AMAGASAKI,HYOGO 661,JAPAN

Publisher:

SCRIPTA TECHNICA PUBL, SILVER SPRING

IDS Number:

RR815

ISSN:

$0882-1666$

SYMMETRY-BASED RECOGNITION OF VEHICLE REARS

KUEHNLE A

\section{PATTERN RECOGNITION LETTERS}

12 (4): 249-258 APR 1991

Document type: Article

Language: English

Cited References: 7

Times Cited: 6

Abstract:

Symmetry is an effective feature for locating vehicle rears. Three symmetry criteria are presented: contour symmetry, gray level symmetry 
and horizontal line symmetry. The application of these criteria to an image yields three histograms which are analyzed to find the vehicle

centerline. The mean error in the vehicle centerline location is generally less than five percent. The contours of the vehicle are followed outward from the centerline to find the vehicle width. The calculated width averages 87 percent of the true width. A nonlinear filter for

edge extraction and an automatic thresholding scheme are also presented. The complete algorithm requires approximately 20 seconds on

a $25 \mathrm{MHz} 80386$ based computer for a 512 by 512 image.

Author Keywords:

SYMMETRY, IMAGE ANALYSIS, VEHICLE RECOGNITION

Addresses:

KUEHNLE A, DAIMLER BENZ AG,FVF-SI GEB QUIST,POSTFACH 800230,W7000 STUTTGART 80,GERMANY

Publisher:

ELSEVIER SCIENCE BV, AMSTERDAM

IDS Number:

FK643

ISSN:

0167-8655

A generic approach to simultaneous tracking and verification in video

Li BX, Chellappa R

IEEE TRANSACTIONS ON IMAGE PROCESSING

11 (5): 530-544 MAY 2002 
Document type: Article

Language: English

Cited References: 39

Times Cited: 0

Abstract:

In this paper, a generic approach to simultaneous tracking and verification in video data is presented. The approach is based on posterior

density estimation using sequential Monte Carlo methods. Visual tracking, which is in essence a temporal correspondence problem, is

solved through probability density propagation, with the density being defined over a proper state space characterizing the object

configuration. Verification is realized through hypothesis testing using the estimated posterior density. In its most basic form, verification

can be performed as follows. Given a measurement vector $\mathrm{Z}$ and two hypotheses $\mathrm{H}-1$ and $\mathrm{H}-0$, we first estimate posterior probabilities

$\mathrm{P}(\mathrm{H}-\mathrm{O} \mathrm{VZ})$ and $\mathrm{P}(\mathrm{H}-1 / \mathrm{Z})$, and then choose the one with the larger posterior probability as the true hypothesis.

Several applications of the approach are illustrated by experiments devised to evaluate its performance. The idea is first tested on

synthetic data, and then experiments with real video sequences are presented, illustrating vehicle tracking and verification, human (face)

tracking and verification, facial feature tracking, and image sequence stabilization.

\section{Author Keywords:}

importance sampling, Monte Carlo method, object verification, visual tracking

Addresses: 
Li BX, Sharp Labs Amer, Camas, WA 98683 USA

Sharp Labs Amer, Camas, WA 98683 USA

Univ Maryland, Ctr Automat Res, College Pk, MD 20742 USA

Publisher:

IEEE-INST ELECTRICAL ELECTRONICS ENGINEERS INC, NEW YORK

IDS Number:

559QA

ISSN:

$1057-7149$

A multimedia data mining framework: Mining information from traffic video sequences Chen SC, Shyu ML, Zhang C, Strickrott J JOURNAL OF INTELLIGENT INFORMATION SYSTEMS

19 (1): 61-77 JUL 2002

Document type: Article

Language: English

Cited References: 22

Times Cited: 0

\footnotetext{
Abstract:

The analysis and mining of traffic video sequences to discover important but previously unknown knowledge such as vehicle identification, traffic flow, queue detection, incident detection, and the spatio-temporal relations of the vehicles at intersections, provide an economic approach for daily traffic monitoring operations. To meet such demands, a multimedia data mining framework is proposed in this paper.
} 
The proposed multimedia data mining framework analyzes the traffic video sequences using background subtraction, image/video segmentation, vehicle tracking, and modeling with the multimedia augmented transition network (MATN) model and multimedia input strings, in the domain of traffic monitoring over traffic intersections. The spatio-temporal relationships of the vehicle objects in each frame are discovered and accurately captured and modeled. Such an additional level of sophistication enabled by the proposed multimedia data mining framework in terms of spatio-temporal tracking generates a capability for automation. This capability alone can significantly influence and enhance current data processing and implementation strategies for several problems vis-a-vis traffic operations. Three real-life traffic video sequences obtained from different sources and with different weather conditions are used to illustrate the effectiveness and robustness of the proposed multimedia data mining framework by demonstrating how the proposed framework can be applied to traffic applications to answer the spatio-temporal queries.

Author Keywords:

multimedia data mining, spatio-temporal relationships, multimedia augmented transition network (MATN), vehicle tracking

KeyWords Plus:

TRACKING

Addresses:

Chen SC, Florida Int Univ, Sch Comp Sci, Distributed Multimedia Informat Syst Lab, Miami, FL 33199 USA

Florida Int Univ, Sch Comp Sci, Distributed Multimedia Informat Syst Lab, Miami, FL 33199 USA

Univ Miami, Dept Elect \& Comp Engn, Coral Gables, FL 33124 USA 
Publisher:

KLUWER ACADEMIC PUBL, DORDRECHT

IDS Number:

$554 \mathrm{CE}$

ISSN:

0925-9902

Detection and classification of vehicles

Gupte S, Masoud O, Martin RFK, Papanikolopoulos NP

IEEE TRANSACTIONS ON INTELLIGENT TRANSPORTATION

SYSTEMS

3 (1): 37-47 MAR 2002

Document type: Article

Language: English

Cited References: 15

Times Cited: 0

\footnotetext{
Abstract:

This paper presents algorithms for vision-based detection and classification of vehicles in monocular image sequences of traffic scenes

recorded by a stationary camera. Processing is done at three levels: raw images, region level, and vehicle level. Vehicles are modeled as rectangular patches with certain dynamic behavior. The proposed method is based on the establishment of correspondences between regions and vehicles, as the vehicles move through the image sequence. Experimental results from highway scenes are provided which
} 
demonstrate the effectiveness of the method. We also briefly describe an interactive camera calibration tool that we have developed for

recovering the camera parameters using features in the image selected by the user.

Author Keywords:

camera calibration, vehicle classification, vehicle detection, vehicle tracking

Addresses:

Gupte S, Sun Microsyst Inc, Palo Alto, CA 94303 USA

Univ Minnesota, Dept Comp Sci \& Engn, Minneapolis, MN 55455 USA

Publisher:

IEEE-INST ELECTRICAL ELECTRONICS ENGINEERS INC, NEW YORK

IDS Number:

539WR

ISSN:

1524-9050

Search of the "Govt Research" Database for "vehicle identification"

$\Gamma \quad \begin{aligned} & \text { Record } 7 \text { of } 764 \text { (FulI) }(0 \\ & \text { marked) }\end{aligned}$

Title:

Genetic algorithms approach to the problem of the automated vehicle identification equipment location. 
Author:

Teodorovic, D.; Van Aerde, M.; Zhu, F.; Dion, F.

Author Address: $\quad$ Teodorovic, D.; Van Aerde, M.; Zhu, F.; Dion, F. [Virginia Polytechnic Instutute and State University, Dept. of Civil and Environmental Engineering, Blacksburg, VA (United States)]

Source:

Journal of Advanced Transportation, 36(1); Win 2002; pp. 1-21 ISSN: 0197-6729

Notes:

CANM

\section{Abstract:}

Automated Vehicle Identification technology allows vehicles equipped with special tags to be detected at specific points in the transportation network without any action by the driver as they pass under a reading station. Benefits of the systems are found in the real-time measurement of traffic patterns, traffic operations and control, reduction of traffic congestion at transportation facilities, transportation planning studies, information and control, electronic toll collection, vehicle identification and other related functions. The objective of this paper is to develop a heuristic model for the optimal location of automated vehicle identification equipment using generic algorithms. A model is proposed and it is tested for the case of a relatively small hypothetical transportation network. Testing the model showed promising results. As the subject of future research other metaheuristic approaches such as simulated annealing and taboo searching have been identified as most important directions. 4 refs., 1 tab., 11 figs. 


\section{Major Topic: \\ ENERGY CONSERVATION, CONSUMPTION, AND UTILIZATION; VEHICLES; IDENTIFICATION SYSTEMS; DATA ACQUISITION SYSTEMS; CONTROL SYSTEMS}

Publication Type: Journal Article

Publication Place: Canada

Intellectual Source: Canada

Language: English

Other Number: $\quad$ DE20255106； JATRDC; TRN: CA0201230

Database: $\quad$ ENERGY SCIENCE \& TECHNOLOGY DATABASE 
Search of the INSPEC data base using "vehicle classification"

\section{Link to... Complete Reference. $\mathrm{UC \text {U-elinks }}$}

\section{Accession Number}

007043625

\section{Author}

\section{Institution}

Harlow C. Shiquan Peng.

\section{Title}

Dept. of Electr. \& Comput. Eng., Louisiana State Univ., Baton Rouge, LA, USA.

Automatic vehicle classification system with range sensors.

\section{Source}

Transportation Research Part C-Emerging Technologies, vol.9C, no.4, Aug. 2001, pp.231-47. Publisher: Elsevier, UK.

\section{Abstract}

Traffic management systems use inductive loop detectors and more recently video cameras to detect vehicles. Loop detectors are expensive to maintain and videobased systems are sensitive to environmental conditions and do not perform well in vehicle classification. Cameras based upon range sensors are not sensitive to lighting and may be less sensitive to other environmental conditions. In addition, range imagery should provide data to form a good basis for vehicle classification applications. In this paper, we describe methods for processing range imagery and performing vehicle detection and classification. A vehicle classification rate of over $92 \%$ accuracy was obtained in classifying vehicles into different vehicle classes. (33 References). 


\section{Accession Number}

007121025

\section{Author}

\section{Institution}

Abdelbaki HM. Hussain K. Gelenbe E.

Sch. of Comput. Sci., Univ. of Central Florida, Orlando, FL, USA.

Title

Source

A laser intensity image based automatic vehicle classification system.

ITSC 2001. 2001 IEEE Intelligent Transportation Systems. Proceedings (Cat.

No.01TH8585). IEEE. 2001, pp.460-5. Piscataway, NJ, USA.

\section{Conference Information}

2001 IEEE Intelligent Transportation Systems. Proceedings. Oakland, CA, USA.

Abstract

25-29 Aug. 2001

This paper presents a laser intensity image based algorithm for automatic vehicle classification system (AVC) on highways. The algorithm performs line by line processing of laser intensity images, produced by laser sensory units, and extracts vehicle features used for the classification. The features include vehicle length, width, height, speed, and some distinguishable patterns in the vehicle profile. The proposed technique outperforms the range data technique in deteriorated atmospheric conditions (such as rain and fog). A software package with a graphical user interface has been developed to illustrate the usage of the classification algorithm and to evaluate its performance. (9 References).

\section{Accession Number}

007189379

\section{Author}

\section{Institution}

Wei Wu. Zhang QiSen. Wang Mingjun.

Title

$$
\text { Dept. of Traffic Eng., Changsha Commun. Univ., China. }
$$

A method of vehicle classification using models and neural networks.

\section{Source}

IEEE VTS 53rd Vehicular Technology Conference, Spring 2001. Proceedings

(Cat. No.01CH37202). IEEE. Part vol.4, 2001, pp.3022-6 vol.4. Piscataway, NJ, USA.

\section{Conference Information}

IEEE VTS 53rd Vehicular Technology Conference. Proceedings. Rhodes, Greece. Abstract 6-9 May 2001.

This paper presents a novel method of vehicle classification using parameterized model and neural networks. First, we propose the parameterized model, which 
can describe the features of vehicle. In this model, vertices and their topological structure are regarded as the key features. Then we adopt a classifier based on multi-layer perceptron networks (MLPN) to recognize vehicles. In this neural network classifier, learning algorithms based on the gradient descent method for the least exponential function error (LEFE) are adopted. Experimental results show that the parameterized model can satisfactorily and effectively describe vehicles, and the correct rate for vehicle recognition using neural networks classifier is more than $91 \%$. This novel method can be used in real world systems such as the vehicle verifying system in toll collecting station. However, it is not difficult to adapt algorithms and improve the model to fit for other traffic scene. (8 References).

\section{Accession Number \\ 007253546 \\ Author \\ Kasprzak W.}

\section{Institution}

Editor

Inst. of Control \& Comput. Eng, Warsaw Univ. of Technol., Poland.

\section{Skarbek W.}

Title

An iconic classification scheme for video-based traffic sensor tasks.

\section{Source}

Computer Analysis of Images and Patterns. 9th International Conference, CAIP

2001. Proceedings (Lecture Notes in Computer Science Vol.2124). Springer-

Verlag. 2001, pp.725-32. Berlin, Germany.

\section{Conference Information}

Computer Analysis of Images and Patterns. 9th International Conference, CAIP Abstract

2001. Warsaw, Poland. 5-7 Sept. 2001.

An application-oriented vision-based traffic scene sensor system is designed. Its most important vision modules are identified and their algorithms are described in detail: the online auto-calibration modules and three optional modules for 2-D measurement tasks (i.e. queue length detection, license plate identification and vehicle classification). It is shown that all three tasks may be regarded as applications of an iconic image classification scheme. Such a general scheme is developed and it can be applied for the above mentioned tasks by exchanging the application-dependent modules for pre-segmentation and feature extraction. The practical background of the described work constitutes the IST project OMNI, dealing with the development of a network-wide intersection-driven model that can take advantage from the existence of advanced sensors, i.e. video sensors and vehicles equipped with GPS/GSM. (12 References). 


\section{Accession Number}

007284435

Author

Institution

Gu Guohua. Bai Lianfa. Chen Qian. Zhang Baomin.

Coll. of Electron. \& Opts., Nanjing Univ. of Sci. \& Technol., China.

Title

Fuzzy pattern recognition in auto vehicle classification based on plane infrared detecting technique.

Source

SPIE-Int. Soc. Opt. Eng. Proceedings of Spie - the International Society for Optical Engineering, vol.4548, 2001, pp.293-6. USA.

\section{Conference Information}

Multispectral and Hyperspectral Image Acquisition and Processing. Wuhan, China. SPIE. Huazhong Univ. Sci. \& Technol. Univ. Bordeaux. Univ.

Abstract

Pennsylvania. Wuhan Univ. et al. 22-24 Oct. 2001.

Automatic vehicle classification (AVC) is the important prerequisite for an automatic charging and administering system. A new AVC system based on an infrared plane detecting technique is introduced, and in order to dispose the data gathered by the infrared detecting system to classify the vehicle, fuzzy pattern recognition technique is used. By this technique, vehicles difficult to be classified by usual method can be classified correctly. (4 References).

Accession Number

007402960

Author

Institution

Wu Yi-Ming. Ye Xiu-Qing. Gu Wei-Kang.

Title

Inst. of Inf. \& Commun. Eng., Zhejiang Univ., Hangzhou, China.

Source

A shadow handler in traffic monitoring system.

Vehicular Technology Conference. IEEE 55th Vehicular Technology Conference.

VTC Spring 2002 (Cat. No.02CH37367). IEEE. Part vol.1, 2002, pp.303-7 vol.1. Piscataway, NJ, USA.

\section{Conference Information}

Vehicular Technology Conference. IEEE 55th Vehicular Technology Conference.

Abstract

VTC Spring 2002. Birmingham, AL, USA. 6-9 May 2002.

A typical shadow-eliminating algorithm is presented. Algorithms for vehicle detection, edge detection and shadow detection are also given. If the shadow is not separated from the vehicle, the next traffic control processes, like vehicle classification, tracking and speed calculation, will be rather difficult. Our 
approach for shadow processing runs in real time in low-cost hardware. The knowledge, such as heading of roads, date and time, can be efficient used in the algorithm. First we detect moving vehicles in a sequence of images. In this way, we need not process the whole image, which saves computation time. Then we separate shades from vehicles using knowledge including results of edges detection, road direction, etc. The results of the algorithm are also given, which shows that this algorithm is quite promising. (12 References).

Accession Number

007025885

Author

Sung-Wook Kim. Kwangsoo Kim. Joo-Hyung Lee. Dong-Il Cho.

Institution

Sch. of Eng. \& Comput. Eng., Seoul Nat. Univ., South Korea.

Title

Application of fuzzy logic to vehicle classification algorithm in loop/piezosensor fusion systems.

\section{Source}

Asian Journal of Control, vol.3, no.1, March 2001, pp.64-8. Publisher: Chinese Automatic Control Soc, Taiwan.

Abstract

Individual vehicle information, especially, vehicle classification data play a key role in advanced traffic management and information systems (ATMIS). In inductive loop and piezo-sensor fusion systems, traffic data such as the vehicle length and the distance between axles are used for vehicle classification.

However, classification errors often occur in distinguishing passenger cars from small trucks and in distinguishing medium-sized trucks from small trucks. It is mainly attributed to the fact that they are similar in lengths and have similar interaxle distances. To improve the performance in vehicle classification, we develop a new algorithm using fuzzy logic. Vehicle weight and speed are used as the inputs to the fuzzy logic block. The output of the fuzzy logic block is a weighting factor to modify the calculated vehicle length. Experimental results show that the developed algorithm significantly improves the classification performance. (17 References). 